\title{
Integration of Training Development Among Schools and Distributed Training Environments
}

\author{
Robert A. Clagg \\ Litton PRC \\ Richard L. Detrani \\ Human Resources Research Organization \\ Billy L. Burnside and Dorothy L. Finley \\ U.S. Army Research Institute
}

Armored Forces Research Unit

Barbara A. Black, Chief

U.S. Army Research Institute for the Behavioral and Social Sciences 5001 Elsenhower Avenue, Alexandria, Virginia 22333-5600

December 1999 